\title{
Déficit fiscal y dinámica económica del Ecuador. Salida del progresismo e implementación de un programa económico con el FMI
}

\author{
URL: http://revistas.uta.edu.ec/erevista/index.php/bcoyu/article/view/841～DOI: http://dx.doi.org/10.31164/bcoyu.21.2019.841 \\ Santiago García -Álvarez \\ Fecha de recepción: 27 de febrero de 2019 \\ Fecha de aceptación: 20 de mayo de 2019
}

\section{Resumen}

El artículo analiza las principales características del déficit fiscal de Ecuador y la aplicación de un programa con el FMI, situación que pondría fin al modelo de crecimiento distributivo y redistributivo implementado durante 10 años por el gobierno de Rafael Correa. Se argumenta que el ajuste macroeconómico es inevitable por la insostenibilidad fiscal. La propuesta gubernamental pretende poner en marcha un nuevo modelo de crecimiento de transición, sustentado en el ajuste fiscal; la inversión privada en reemplazo de la inversión pública; apalancamiento de las exportaciones no petroleras; la baja intervención del Banco Central; y un fuerte proceso de liberalización del mercado de trabajo.

Palabras clave: Política fiscal; crecimiento económico; economía ecuatoriana.

\section{Abstract}

The aim of this article is to analyze the main characteristics of Ecuador's fiscal deficit and the application of an International Monetary Fund program. This alternative would put an end to the distributive and redistributive growth model implemented for 10 years by the government of Rafael Correa. The main argument is that macroeconomic adjustment is inevitable, due to the strong conditions of fiscal unsustainability. The governmental proposal intends to launch a new model of transition growth, based on fiscal adjustment; private investment in replacement of public investment; promotion of non-oil exports; the low intervention of the Central Bank of Ecuador in the monetary-financial areas; and a strong process of labor market liberalization.

Keywords: Fiscal policy; economic growth; Ecuadorian economy.

\section{Introducción}

El modelo de crecimiento del gobierno de Rafael Correa (2007-2016) se sustentó en una pronunciada expansión fiscal, a su vez, este crecimiento económico fue la base material para una activa política de distribución y redistribución del ingreso, con efectos apreciables tanto en la reducción de la pobreza, así como en los niveles de inequidad². Sin embargo, el grave choque externo sufrido por el país en 2014 y 2015 llevó a un inevitable ajuste fiscal que dejó sin piso al modelo de crecimiento antes mencionado, ya que se sintió con dureza la reducción de los precios internacionales del petróleo y la apreciación del dólar; mientras que en lo interno, se sufrió fuertes efectos negativos por el terremoto de abril de 2016.

En términos generales, el contexto internacional ha sido adverso para la mayoría de países latinoamericanos, a partir de la gran crisis financiera internacional de 2008, debido a la finalización del ciclo ascendente de los commodities y por la ralentización de la economía global, especialmente de los países desarrollados (CEPAL, 2018a; FMl, 2018, 2016 a y b). Esta situación provocó condiciones de cierta manera dramáticas para Ecuador, pues, en el corto plazo, vio caer su producción y, en el mediano plazo, un empeoramiento de sus principales indicadores sociales (FMI, 2016b).

De otra parte, una vez finalizado el ciclo político de la revolución ciudadana impulsada por el ex presidente Rafael Correa, la ciudadanía ecuatoriana reconoció los procesos políticos de reforma institucional implementados por el gobierno presidido por Lenin Moreno, en funciones desde mayo de 2017, pero dejó sentada su inconformidad con los procesos económicos, en la medida que se retrasaron las definiciones necesarias para enfrentar los problemas económicos heredados del pasado, especialmente el desequilibrio fiscal. Una interpretación de esta situación podría ser que, frente a la debilidad política del partido Alianza País, casi inmediatamente luego de la ganancia de las elecciones y sus repercusiones en la Asamblea Nacional, el gobierno de Moreno ha buscado en este tiempo poner ciertas bases políticas de respaldo mínimo para emprender un proceso de transición económica.

En tales condiciones, la pregunta importante es: ¿de qué manera y bajo qué mecanismos se podría implementar un modelo de crecimiento económico tutelado o negociado con el Fondo Monetario Internacional (FMI) de transición, que debería enfrentar los graves desequilibrios existentes, especialmente en el ámbito fiscal, pero además una apreciable vulnerabilidad externa que se expresa en la cuenta corriente de balanza de pagos y una frágil recuperación económica sin arrastre en la generación de empleo adecuado?

En el debate político y económico de los últimos 18 meses, tiempo en el cual el gobierno no ha propuesto un plan económico estructurado, se discutieron dos opciones, de un lado, volcarse hacia un modelo de crecimiento de base ortodoxa, con ajustes importantes en el sector fiscal, la reducción de impuestos internos, la flexibilización laboral, una agenda agresiva de apertura comercial y un énfasis en la atracción de IED hacia los sectores estratégicos de la economía nacional, todo ello bajo una posible asistencia del FMl a través del Fondo de Facilidad Extendida (Extended Fund Facility). La otra opción era la puesta en marcha de un modelo de crecimiento de tipo heterodoxo, con un ajuste fiscal progresivo; reformas mínimas al mercado de trabajo; papel activo del Banco Central del Ecuador sobre la liquidez de la economía nacional; sostenimiento de una política social activa; sostenimiento de la inversión pública; entre otros.

Con el anuncio de los lineamientos de un programa económico realizado a inicios de abril de 2018 y con la expedición de la Ley Orgánica de Fomento Productivo, Atracción de Inversión, Generación de Empleo, Estabilidad y Equilibrio Fiscal, en agosto de 2018, y el anuncio de medidas económicas en el cuarto trimestre del año mencionado, la decisión siempre estuvo encaminada por la primera opción relacionada con el FMI. En tales condiciones, este trabajo tiene como principal objetivo analizar la propuesta de reforma económica que el gobierno de Lenin Moreno intenta poner en marcha luego de casi dos años de funciones, que pondría fin a un modelo de crecimiento distributivo y redistributivo de corte progresista que implementó el ex presidente Rafael Correa (2007-2016), pero cuyas bases fiscales y de sostenibilidad en el tiempo eran muy débiles, tal como se argumentará más adelante.

La principal hipótesis es que el ajuste macroeconómico es inevitable, lo cual conduciría a un cambio importante del modelo de crecimiento imperante en los últimos diez años, en una nueva lógica que se sustentaría en un enfoque combinado de demanda agregada vía recuperación y liderazgo de la inversión privada y un fuerte apalancamiento de las exportaciones, sobre todo, no petroleras; y de oferta agregada, con la recuperación de la producción interna a partir de los beneficios tributarios y la apertura gradual de importaciones, todo ello bajo un acuerdo de crédito con el FMI, como una de las principales fuentes de financiamiento de la transición.

Universidad Central del Ecuador. Docente de la Facultad de Ciencias Económicas. Quito-Ecuador. E-Mail: sgarciaa@uce.edu.ec. ORCID: https://orcid.org/0000-0002-3244-738X

2El desempeño económico favorable del período 2007-2014 (variación positiva del PIB de 3,4\% anual promedio) fue el sustento para poner en marcha un considerable proceso distributivo y redistributivo, el primero expresado por una mayor participación de sueldos y salarios en el ingreso nacional, y el segundo, expresado en un conjunto de políticas sociales que permitieron una reducción apreciable de los niveles de pobreza e inequidad y del desempleo abierto. A la par se implementó un modelo fundamentado en una fuerte inversión pública para la generación de infraestructura como base para la redefinición de la configuración productiva de la economía ecuatoriana (García, 2016). 
Una segunda suposición es que inevitablemente la demanda interna va a decaer por vía de priorización del gasto corriente y de la inversión pública (niveles mínimos en relación al PIB), lo que traería impactos recesivos, pero, quizá, manejables en el sentido de que no darían paso a una gran crisis económica, pero si a una ralentización de la economía. Sin duda, las complicaciones económicas van a provocar una fuerte protesta social e inestabilidad política.

Con estas consideraciones, el artículo contiene cinco partes: i) un breve abordaje teórico sobre las relaciones entre crecimiento económico y déficit fiscal; ii) la metodología aplicada; iii) el análisis de resultados en lo relacionado a la situación macroeconómica de Ecuador, los principales indicadores del problema fiscal, los principales elementos de políticas implementadas por el gobierno nacional; y, iv) las principales conclusiones.

\section{Metodología}

Desde el punto de vista metodológico, este trabajo es eminentemente bibliográfico bajo la técnica de referencias cruzadas, que se aplicó a un considerable conjunto de estudios, informes y reportes relacionados con el crecimiento económico, la macroeconomía, el ajuste fiscal y la vulnerabilidad externa del Ecuador. El enfoque teórico utilizado es de Economía Política, en vista de que se da importancia al proceso histórico subyacente que explica el parte la situación actual, y al juego o lucha política al interior del país, con la emergencia de grupos hegemónicos antes minimizados por el gobierno de Correa. En la parte empírica se efectuó un cálculo de la sostenibilidad fiscal aplicado al caso ecuatoriano.

\section{Marco teórico. Déficit fiscal, crecimiento económico y garantía de derechos sociales}

En el debate económico suele asociarse, casi de manera instintiva y exclusiva, el problema fiscal con el déficit, configurando de esta manera una visión restringida, cuando en realidad, los temas fiscales deben analizarse en su integralidad, es decir, no solo en el resultado final (déficit/superávit) sino en sus ingresos, egresos y financiamiento. Inclusive, el déficit fiscal no debería verse como un problema en sí mismo, si se considera que, si bien se expresa en una cifra estadística, desde una perspectiva de Economía Política, los resultados fiscales muestran la posibilidad o no de financiar derechos sociales, mantener fuentes de empleo y honrar los compromisos de endeudamiento público. Esta versión de política fiscal es relevante para el análisis del progresismo económico del gobierno de Rafael Correa, que en la práctica mantuvo durante todos sus periodos de gobierno un permanente déficit fiscal. Pero un déficit fiscal no podría ser hacia el infinito pues tarde o temprano provoca una gran inestabilidad a todo el sistema económico interno, tal como se explica en las siguientes líneas.

En América Latina, la CEPAL (2018c) ha puntualizado con cierta insistencia en sus publicaciones que la inequidad social es económicamente ineficiente, ya que se convierte en una trabaja para la productividad, la fiscalidad, la sostenibilidad ambiental y la difusión de la sociedad del conocimiento. Las alternativas para enfrentar a la inequidad se fundamentan en varios aspectos: i) la puesta en marcha de una macroeconomía para el desarrollo (estabilidad monetaria y estabilidad financiera; fiscalidad para el crecimiento y la igualdad); ii) Estado de bienestar para el ejercicio de los derechos y aumento de la productividad (protección del gasto público social mediante una tributación progresiva; readecuación de la educación al nuevo contexto tecnológico; fortalecimiento de los sistemas de protección social y cuidado; e ingreso básico) y iii) descarbonización (digitalización, ciudades sostenibles y energías renovables).

En la parte que nos interesa en este trabajo, la puesta en marcha de una macroeconomía para el desarrollo implicaría poner por delante la estabilidad monetaria y estabilidad financiera; alcanzar una adecuada fiscalidad con un doble propósito, la no afectación del crecimiento económico y, al mismo tiempo, la puesta en marcha de bases materiales para la igualdad o equidad social (CEPAL 2018c). Este punto es precisamente el que sirve como sustento para criticar la inviabilidad del modelo de crecimiento del anterior presidente.
Por su parte, el post keynesianismo es una escuela de pensamiento heterodoxa que se desarrolla a mediados de los años 1950 e incluye un conjunto de planteamientos empíricos y teóricos que siguen una línea de investigación amplia y sustentada en los principios keynesianos y los desarrollos posteriores de al menos cinco corrientes relacionadas con Kalecki, Sraffa, Kaldor, entre otros (Ponsot, 2017). De los planteamientos post keynesianos, los aspectos relevantes para esta investigación son: la presencia de la inestabilidad como norma frecuente de la actividad económica; la relevancia de la demanda efectiva; el carácter endógeno del dinero y la importancia fundamental de la distribución equitativa del ingreso para nivelar oportunidades para los estratos sociales medios y bajos (Lavoie, 2009)

El crecimiento económico se realiza en condiciones de desequilibrio más que de equilibrio, pues los agentes económicos interactúan en el mercado no bajo la forma de expectativas racionales, sino deben enfrentar eventos futuros inciertos, por lo que el conjunto de decisiones es diverso e imprevisible. No existe la figura del agente representativo que propone la economía convencional u ortodoxa, tampoco prima la libre competencia en el mercado.

En tanto que el nivel económico depende fundamentalmente de la demanda agregada efectiva, es decir, la producción se ajusta a la demanda y no está restringida por la oferta ni por la cantidad de dotación de factores productivos (Lavoie, 2009). En cuanto a la endogeneidad de dinero, el punto de arranque es la consideración de que el dinero no es neutro como lo supone la economía neoclásica, por el contrario, la moneda está altamente ligada a la producción, dando paso a una economía monetaria de producción. En estricto orden de cosas, los contratos, las deudas y los activos están definidos en una determinada unidad monetaria. En lo concerniente a la importancia de la repartición del ingreso, el post keynesianismo asume que existen conflictos de repartición del ingreso y que el conflicto distributivo en favor de las clases sociales altas reduce las oportunidades para los estratos sociales medios y bajos.

\section{Resultados}

Ecuador mantuvo un apreciable crecimiento económico en el periodo 2007-2014, aproximadamente 4,4\% de variación del PIB en términos reales, pero desde el tercer trimestre de 2015 hasta el tercer trimestre de 2016 se contabilizaron 5 periodos con una variación trimestral negativa (interanual t-4); luego una ligerísima recuperación al finalizar el 2016. Posteriormente las variaciones trimestrales fueron positivas durante 2017 hasta alcanzar un crecimiento de 2,4\% anual promedio, con lo cual se rompió el comportamiento negativo de la actividad económica de años anteriores, pero se puso en vigencia un ritmo de crecimiento económico bajo en términos reales. Las previsiones del Banco Central del Ecuador (BCE) establecen una variación positiva de $1,2 \%$ durante 2018 y $1,4 \%$ en 2019 . Ver figura 1.

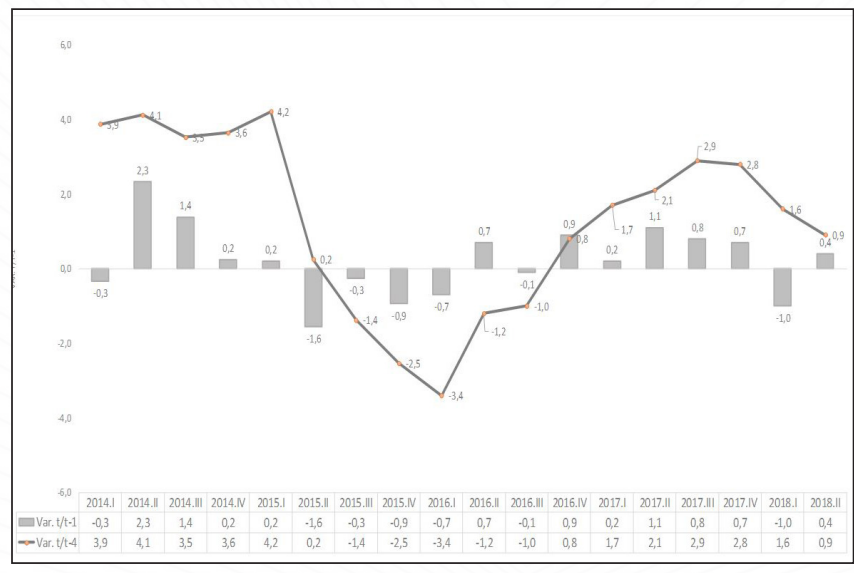

Fuente: BCE (2018) Figura 1. PIB real. Tasas de variación trimestral 
En materia de precios, si bien la inflación esperada se estimó en promedio inferior a 2,8\%, en casi todos los documentos oficiales, las cifras recientes muestran un fenómeno muy preocupante, pues la inflación anual llegó a 1,12\% en diciembre de 2016; -0,2 en diciembre de 2017 y 0,27\% en diciembre de 2018 (BCE, 2018). Esta situación, en principio, no estuvo prevista y, sin duda, complejiza el manejo macroeconómico, debido a las interrelaciones que tiene una caída del nivel general de precios internos en las inversiones privadas y en la recreación de una débil demanda interna.

La pobre dinámica económica de los últimos tres años provocó un deterioro del mercado de trabajo, por el comportamiento negativo de sus principales indicadores; así, la tasa de desempleo nacional en los años 2016-2018 tuvo la siguiente dinámica: 5,2\%; 4,6\% y 3,7\%, respectivamente; la tasa de empleo adecuado nacional pasó dentro del periodo señalado de $41,2 \%$ a $42,3 \%$ y $40,6 \%$; mientras que la tasa de empleo inadecuado nacional se elevó de 53,4\% a 52,9\% y 55,2\% (INEC, 2018a).

Al final de este proceso, se puede detectar presión al incremento de la pobreza, tal como lo muestran los datos para los mencionados años, en la medida que la incidencia de extrema pobreza nacional por ingresos pasó de 16,5\% en 2017; 8,6\% en 2013; 8,7\% en 2016 a 8,4\% en 2018, rompiendo de esta forma una prolongada tendencia a la baja, que fue uno de los principales signos de una política económica progresista (INEC, 2018b).

El déficit fiscal global ha sido una constante desde 2006 en adelante, llegando a niveles apreciables de 4,2\% del PIB en 2013; 7,2\% en 2014; $5,3 \%$ en 2016 y 3,3\% en 2017. Precisamente, cuando empezó la fase recesiva de la economía nacional (2015) se aceleraron estos niveles deficitarios, todo lo cual demuestra que una vez que se produce la retracción económica, se presenta una inflexibilidad presupuestaria que al final del día termina en déficit considerables (véase figura 2). Este análisis llevado al déficit primario, en el periodo 2011-2017, solo en 2011 y 2015 se presentaron superávit de 0,3\% y 0,1\% con relación al PIB, respectivamente. El resto de años fueron resultados negativos, en 2014 el déficit primario llegó a 5,8\% del PIB.

\begin{tabular}{|c|c|c|c|c|c|c|c|}
\hline 0,0 & & & & & & & \\
\hline$-0,5$ & 2011 & 2012 & 2013 & 2014 & 2015 & 2016 & 2017 \\
\hline$-1,0$ & & & & & & & \\
\hline$-1,5$ & $-0,6$ & & & & & & \\
\hline$-2,0$ & & & & & $-1,7$ & & \\
\hline$-2,5$ & & $-2,0$ & & & & & \\
\hline$-3,0$ & & & & & & & \\
\hline$-3,5$ & & & & & & & $-3,3$ \\
\hline$-4,0$ & & & & & & & \\
\hline$-4,5$ & & & $-4,2$ & & & & \\
\hline$-5,0$ & & & & & & & \\
\hline$-5,5$ & & & & & & -53 & \\
\hline$-6,0$ & & & & & & & \\
\hline$-6,5$ & & & & & & & \\
\hline$-7,0$ & & & & & & & \\
\hline$-7,5$ & & & & $-7,2$ & & & \\
\hline$-8,0$ & & & & & & & \\
\hline
\end{tabular}

Fuente: Fuente: BCE (2018)

La expansión del gasto público en Ecuador se ha fundamentado en los siguientes rubros en orden de importancia: inversión pública, seguido por el pago de sueldos y salarios y luego el rubro correspondiente al gasto social. Un elemento fundamental en el análisis del presupuesto público tiene que ver con el gasto de inversión, este punto es quizá uno de los principales elementos de la política fiscal que se implementó en el periodo 2007-2016. En realidad, Ecuador se convirtió en uno de los países latinoamericanos de mayor nivel de inversión pública en la región, con niveles que llegaron a bordear 8-9\% del PIB, cuando el promedio latinoamericano llegaba a 6\% del PIB (CEPAL, 2018b, 2017, 2016).

Por tanto, queda en evidencia, que el ajuste fiscal desde 2014 en adelante se basó en la disminución de la inversión pública por la imposibilidad fáctica de financiarla, con lo cual esta variable no ha jugado un rol contra-cíclico, excepto en los años de la crisis financiera internacional, cuando la actividad económica del país descendió a un crecimiento mínimo de $0,6 \%$ en 2009, en contraste con el crecimiento de $6,4 \%$ en 2008 ; pero en tales circunstancias, de todos modos el gasto de inversión se incrementó

Los sueldos y salarios han llegado a representar cerca del 9\% del PIB en todos estos años, pero el problema está en que este rubro se ha convertido en un gran peso en toda la estructura del gasto público, cuyo manejo resulta inflexible pues no podrían vulnerarse derechos de los trabajadores y empleados. En tal sentido, el tema es si el tamaño de la burocracia realmente responde a las verdaderas necesidades de la sociedad ecuatoriana ${ }^{3}$. Desde un punto de vista macroeconómico, este apreciable peso del gasto en sueldos y salarios comprometen cerca del 30\% de los recursos fiscales, que al final del día alteran las posibilidades de un manejo contra-cíclico, especialmente en la imposibilidad de sostener una adecuada inversión pública. Evidentemente bajo estas condiciones es más fácil políticamente ajustar la inversión que el gasto corriente en salarios ${ }^{4}$.

Si bien se explicó en líneas anteriores que el déficit fiscal del presupuesto general del estado llegó en promedio a 5\% del PIB en los últimos 4 años, no es menos cierto que el financiamiento global alcanzó $7 \%$ del PIB en 2016 y 13\% en 2017 (incluyendo amortizaciones, atrasos a proveedores y anticipos petroleros). Esta magnitud de recursos impone una gran presión a las autoridades gubernamentales para su financiamiento y, en fases recesivas del ciclo económico, termina con la contratación inevitable de endeudamiento público.

El endeudamiento público consolidado ha tomado un ritmo creciente desde 2010 en términos comparativos con el PIB, puesto que pasó de una relación del 19\% en el mencionado año a 39\% en 2016, 41\% 2017 y $45 \%$ en diciembre de 2018 . Se hace necesario detenerse un poco más en el conjunto de cifras alrededor del endeudamiento público que recoge la deuda interna más la deuda externa, pues hay que contextualizarlas en la realidad de Ecuador. En efecto, el año con mayor relación deuda/PIB fue 1999, aproximadamente $86 \%$, para luego ir descendiendo hasta llegar a 27\% en 2007 y 16\% en 2009, para luego empezar una nueva tendencia alcista considerable, tal como se acaba de mencionar en líneas anteriores. En el marco de este comportamiento ascendente, debe tomarse en cuenta que el PIB de 1998 comparado con 2006 se multiplicó por 1,7 veces en términos nominales, mientras que similar comparación entre 1998 y 2015, se multiplicó por 3,6 veces, es decir, la actividad económica ha mantenido una tendencia alcista apreciable desde la dolarización.

Lo que se quiere poner en relieve es que los niveles de endeudamiento público casi siempre fueron un gran problema para las finanzas públicas ecuatorianas, en términos de asegurar la necesidad capacidad de pago (solvencia), que en los años 80 y 90 del siglo anterior se resolvió mediante drásticas reducciones del gasto social y la inversión pública (Santos Alvite, 1987).

Ahora bien, el tema de la sostenibilidad fiscal se vuelve un tema crítico en las condiciones adversas señaladas. En la tabla 1, se intenta una cuantificación de este indicador entendido como capacidad de pago a compromisos internos y externos, de lo cual se desprende que la deuda pública agregada llegó a 39\%, 41\% y 45\% del PIB en 2016, 2017 y 2018 (octubre), respectivamente, con un mayor peso del endeudamiento externo, que prácticamente triplica a la deuda interna.

Según cifras oficiales, el gasto de remuneraciones en el presupuesto público se reparte de la siguiente manera: educación, 37\%; salud, 17\%; defensa nacional, 13\%; asuntos internos, 16\%; jurisdiccional, 5\% y otros, 12\%. Los tres primeros rubros, educación, salud y defensa nacional concentran 67\% del total (MEF, 2017)

${ }^{4}$ En el marco de la programación cuatrianual 2017-2020, los sueldos y salarios alcanzan un valor de 9,3 mil millones de dólares en promedio, sin ninguna tendencia a su reducción. Déficit fiscal y dinámica económica del Ecuador. Salida del progresismo e implementación de un programa económico con el FMI 
El servicio de este endeudamiento agregado llegó al 8\% del PIB en 2016, en una tendencia creciente en el transcurso del tiempo, superando de esta manera al gasto social educación que en el mismo año equivalió al $5 \%$ del PIB. En términos comparativos con respecto a las exportaciones totales de Ecuador, el servicio de la deuda equivalió a $48 \%$ en 2016, es decir, casi la mitad de todas las ventas que realiza el país en los mercados internacionales, incluido el petróleo. El saldo de la deuda agregada equivalió a 1,53 veces las exportaciones totales en el año mencionado, duplicándose esta relación si se toma en cuenta el año 2014. En 2017, esta relación fue de 1,65 veces.

Tabla 1. Indicadores de sostenibilidad fiscal del Ecuador. Presupuesto del gobierno central, base caja, cifras en \% del PIB y en millones de US\$. Periodo 2014-2017

\begin{tabular}{lrrrr}
\hline & $\mathbf{2 0 1 4}$ & $\mathbf{2 0 1 5}$ & $\mathbf{2 0 1 6}$ & $\mathbf{2 0 1 7}$ \\
\hline & En porcentajes & & & \\
Saldo deuda pública agregada / PIB & 30 & 33 & 39 & 45 \\
D. Interna / PIB & 12 & 13 & 13 & 14 \\
D. Externa / PIB & 17 & 20 & 26 & 31 \\
Servicio Deuda / PIB & 5 & 7 & 8 & 9 \\
Intereses / PIB & 1 & 2 & 2 & 2 \\
Amortizaciones / PIB & 4 & 6 & 6 & 7 \\
Servicio Deuda Externa / Exportaciones & 19 & 40 & 48 & 49 \\
Saldo Deuda Extema / Exportaciones & 68 & 110 & 153 & 165 \\
& En millones de US\$ & & & \\
& 30.140 & 32.771 & 38.137 & 41.553 \\
Deuda pública agregada & 12.558 & 12.546 & 12.457 & 9.927 \\
D. Interna & 17.582 & 20.225 & 25.679 & 31.627 \\
D. Externa & 4.936 & 7.351 & 8.134 & 9.463 \\
Servicio Deuda & 1.362 & 1.762 & 1.931 & 2.515 \\
Intereses & 3.574 & 5.589 & 6.203 & 6.948 \\
Amortizaciones & 101.726 & 99.290 & 98.614 & 103.056 \\
PIB & 25.724 & 18.331 & 16.798 & 19.122 \\
\hline Exportaciones & & & $F u e n t e: B C E$
\end{tabular}

Fuente: $B C E(2018)$

Las autoridades gubernamentales han ensayado una estrategia de ajuste gradual del déficit fiscal y ha interpuesto un conjunto de medidas relacionadas con la reactivación económica, lamentablemente sin buenos resultados, debido tanto a la tardanza en su implementación a través de la Ley Orgánica de Fomento Productivo, Atracción de Inversión, Generación de Empleo, Estabilidad y Equilibrio Fiscal, recién expedida a 15 meses de inicio de su gestión, así como a su excesiva confianza en la entrega de incentivos tributarios como palanca de promoción de la inversión privada. Esta ley es la base fundamental del quehacer gubernamental en materia económica y contiene cuatro grandes ámbitos: i) régimen de remisiones y reducciones de deudas frente al fisco; ii) incentivos a las inversiones privadas; iii) incentivos a la construcción de vivienda de interés social; y iv) reglas macro-fiscales para la estabilidad fiscal y limitación al endeudamiento público.

La remisión tributaria implica la condonación del 100\% de intereses, multas y recargos derivados del saldo de las obligaciones tributarias o fiscales Internas que corresponden a la administración del Servicio de Rentas Fiscales (SRI), así como para otras entidades como la seguridad social y las aduanas ${ }^{5}$. En materia de incentivos para la atracción de inversión privada, se establecen varias medidas de carácter tributario, destacándose la exoneración por 12 años del pago del impuesto a la renta y de su anticipo para nuevas inversiones productivas en sectores priorizados, excepto en Quito y Guayaquil donde el beneficio es de 8 años. Se dispone una exoneración del impuesto a la renta por 15 años para las nuevas inversiones productivas que se ejecuten en los sectores priorizados industrial, agroindustrial y agro-asociativo dentro de los cantones ubicados en zonas de frontera.

En el caso de proyectos de construcción de vivienda de interés social, se aplican los incentivos mencionados a las inversiones y se exige la vigencia de procedimientos administrativos simplificados dentro de los trámites municipales. Además, todos los servicios de construcción de vivienda de interés social tendrán tarifa 0\% del IVA. De otro lado, los exportadores habituales tienen derecho a la devolución de los pagos realizados por concepto de impuesto a la salida de divisas (ISD) en la importación de materias primas, insumos y bienes de capital, con la finalidad de que sean incorporados en procesos productivos de bienes que se exporten. Para alcanzar una ampliación del acceso al crédito productivo y crédito de inversión, se propone que la banca pública constituya de sus utilidades, un fondo de garantías para fomento productivo, con énfasis en el sector asociativo.

Todo lo anterior se complementa con otras políticas, las cuales, si bien no constan en la ley previamente señalada, tienen que ver con ámbitos importantes para la actividad económica, como en el caso de la propuesta que, ya está en vigencia, sobre nuevas modalidades de contrato de trabajo, con énfasis en sectores turismo, agrícola, pesquero; la racionalización de costos a las transacciones dentro del mercado de valores, la reducción del tamaño del Estado mediante supresión o fusión de entidades gubernamentales y empresas públicas.

En el ámbito de las finanzas públicas, esta ley establece mecanismos para asegurar la sostenibilidad de la deuda externa y los límites de endeudamiento; al respecto, el saldo de la deuda pública total no podrá superar el equivalente al $40 \%$ del PIB. Una vez que la deuda haya vuelto al límite permitido por ley (a finales de diciembre de 2018 esta relación llegó a 45\% del PIB), no se podrá aprobar presupuestos ni con déficit primario ni con un resultado global que no cumpla con la meta estructural de largo plazo (no se podría superar la tasa de crecimiento de largo plazo de la economía). Además, se establece que los ingresos provenientes de la explotación de recursos naturales no renovables que superen a lo contemplado en el Presupuesto General del Estado se destinarán a la generación de un fondo de estabilización fiscal que permita garantizar la sostenibilidad de las cuentas públicas y principalmente de los programas sociales.

Las reglas macro-fiscales podrán ser suspendidas temporalmente cuando ocurran catástrofes naturales, recesión económica grave desequilibrios en el sistema de pagos, o situaciones de emergencia nacional, para ello requerirán la aprobación de la Asamblea Nacional con la mayoría absoluta de sus miembros. Estas reglas también se podrán suspender en caso de que el Presidente de la República decrete estado de excepción, conforme a lo dispuesto en la Constitución ${ }^{6}$.

En el transcurso del tiempo el gobierno nacional, al finalizar el año 2018, tomó varias medidas relacionadas con la reducción de los subsidios a los combustibles ${ }^{7}$, la reducción de $10 \%$ de los salarios de ministros y viceministros y $5 \%$ de las escalas superiores de la burocracia, la eliminación definitiva de vacantes en la administración pública y la gestión de mayor endeudamiento directo con China. Todo ello bajo la perspectiva de alcanzar una reducción del déficit fiscal global de 3 puntos con respecto al PIB, toda vez que este déficit llegó a $6 \%$ del PIB en 2017. Todas estas medidas no han generado confianza en los mercados internacionales y el $\mathrm{EMB|}{ }^{8}$ volvió a subir a finales del 2018.

${ }^{5}$ A inicios de enero de 2019, el SRI reportó una recaudación por remisión tributaria de 1.091 millones de dólares (aproximadamente $1 \%$ del PIB nominal), con un total de 25 mil sociedades beneficiadas y 326 mil personas naturales. Aunque no todo corresponde a recaudación en efectivo, no cabe duda que este mecanismo superó la meta prevista de 600 millones de dólares. Llama también la atención del gran número de contribuyentes naturales beneficiados. De antemano se conocía que en proporción de los valores a recaudar correspondía a grandes empresas deudoras. ${ }^{6}$ En vista de que se parte de una situación fiscal complicada, la propia Ley de Fomento Productivo establece un periodo de transición hasta 2021 , a fin de cumplir con las disposiciones de ajuste fiscal. Por otro lado, es importante señalar que esta disposición deja un espacio político al presidente de la república para suspender un programa de consolidación fiscal en el caso de que sea inmanejable. Posiblemente todo ello podría entrar en contradicción con un acuerdo formal con el FMI.

${ }^{7}$ Aproximadamente en 2 décadas no se han revisado los precios oficiales de los combustibles que conllevan un fuerte subsidio estatal, debido a la necesidad de importación de naftas y diésel. Según un estudio de profesores de IAEN y University of Essex, estos subsidios a los combustibles son innegable y socialmente regresivos, excepto el subsidio al gas doméstico (Jara et al, 2018 ) ${ }^{8} E \mathrm{E}$ EMBI (Emerging Markets Bonds Index), que mide el sobre-precio que paga un país para financiarse en el mercado de capitales en relación a los bonos de Estados Unidos, se ubicó en 459 puntos en enero de 2018, luego ascendió a 748 puntos el 14 de mayo; 762 puntos el 11 de septiembre, pese a las medidas económicas ya anunciadas por el presidente Moreno; 826 puntos el 31 de diciembre del mismo año. En 2019, bajó a 703 puntos el 30 de enero y volvió a bajar a 611 puntos el 24 de febrero, cuando ya se hizo oficial el proceso de negociación con el FMI. Déficit fiscal y dinámica económica del Ecuador. Salida del progresismo e implementación de un programa económico con el FMı 
El propio FMl acepta que todo programa de consolidación fiscal suele reducir el producto (sesgo recesivo) y aumentar el desempleo en el corto plazo, pero en el mediano y largo plazo, existen beneficios para la reactivación económica a través de las reducciones de tasas de interés, la disminución del valor de la moneda (depreciación o devaluación) y el aumento de las exportaciones netas (saldo comercial). Al respecto:

(...) La consolidación fiscal suele tener un efecto contractivo sobre el producto. En dos años, una consolidación fiscal equivalente a $1 \%$ del PIB tiende a reducir el PIB en aproximadamente 0,5\% y a elevar la tasa de desempleo en alrededor de 0,3 puntos porcentuales. La demanda interna -consumo e inversión - se reduce aproximadamente 1\% (FMI 2010: 104)

Tal como se mencionó en los párrafos anteriores, si bien el FMI se plantea las preguntas correctas en cuanto a los efectos a corto plazo del ajuste fiscal sobre la actividad económica, sin embargo, sus propias respuestas se basan en la perspectiva económica ortodoxa, que implica una plena confianza en los equilibrios de los mercados. Desde un punto de vista crítico, existen otras preguntas a más de los costos del ajuste y que tienen que ver con los siguientes aspectos: i) las condiciones del ajuste por medio de la reducción del gasto público o por el incremento de los ingresos fiscales (mayores recaudaciones tributarias); ii) los posibles impactos directos del ajuste fiscal sobre el empleo; iii) las posibles medidas de política monetaria relacionadas con la liquidez para compensar la caída de la actividad económica; iv) los posibles usos del ahorro nacional generado por la disminución de los pagos de intereses y amortizaciones de la deuda pública al recibir recursos a mayores plazos y menores tasas de interés.

El FMl argumenta que el ajuste fiscal en los países que afrontan un mayor riesgo percibido de incumplimiento soberano tiende a ser menos contractivo (este sería el caso de Ecuador como se mencionó en la introducción), toda vez que la disminución de los niveles de deuda pública podrían reducir las tasas de interés reales, lo que estimula la inversión privada. Una vez que se logra la estabilización de la economía, se crean espacios fiscales para reducir los impuestos, especialmente los impuestos sobre la renta del capital, entonces ambos efectos aumentan el producto a largo plazo; así, por cada reducción de 10 puntos porcentuales de la relación deuda/PIB, el producto aumenta aproximadamente 1,4\% a largo plazo (FMI 2010). En suma, los efectos positivos sobre la confianza compensarían los impactos contractivos sobre la demanda agregada.

Otras medidas del "paquete fondomonetarista" a más de lo fiscal tocarían los siguientes ámbitos: i) financiero-monetario; ii) sector externo y iii) mercado de trabajo. En lo monetario-financiero se busca una liquidez suficiente en el sistema bancario y recortes en las tasas de interés para promover inversiones, además eliminación de regulaciones sobre encajes para liquidez doméstica de los bancos y apertura a sucursales de bancos extranjeros. En lo externo, las estrategias se dirigen al manejo de la sobrevaloración de la moneda, en este caso el dólar, a través de reducción de los costos internos (salarios) y cambios de impuestos directos a impuestos indirectos, adicionalmente la apertura comercial que implique saldos positivos permanentes en la balanza comercial. En cuanto al mercado de trabajo, las medidas económicas deben garantizar su liberalización (eliminación de contratación indefinida e impulso de contratación por horas).

\section{Conclusiones}

La política económica del gobierno de Lenin Moreno apunta a un desmantelamiento del modelo de crecimiento económico distributivo y redistributivo impulsado por el ex presidente Rafael Delgado en el periodo 2007-2016, en parte, debido a la insostenibilidad fiscal que imposibilita en la práctica mantenerlo y, evidentemente, por el cambio de la correlación de fuerzas políticas en favor de los sectores conservadores y hegemónicos; los cuales buscan en contra partida, la puesta en marcha de un modelo de crecimiento liderado por el sector privado, que contendría los siguientes elementos: un profundo achicamiento del Estado, que reduzca a mínimos el gasto público como soporte de los equilibrios fiscales; una mayor independencia del Banco Central del Ecuador en e ámbito monetario-financiero para evitar la colocación de bonos y certificados estatales; una mayor apertura comercial internacional basada en promoción de exportaciones vía acuerdos comerciales y liberalización de importaciones; varias reformas para liberalizar el mercado de trabajo, especialmente la reducción de los costos de despido; y reformas para la liberalización de la cuenta de capitales de la balanza de pagos. En definitiva, una mayor presencia del sector privado como principal actor económico en un contexto de apertura y liberalización interna.

No se podría negar, tal como se ha señalado en este artículo, la sostenibilidad fiscal llegó a sus límites en estos tres últimos años, debido a que se han venido incrementando inconteniblemente los recursos para el servicio del endeudamiento público (interno y externo) y porque ha llevado a mínimos la inversión pública como principal variable de ajuste. La pretensión del gobierno es apuntalar la sostenibilidad fiscal, como uno de los elementos centrales de su estrategia económica, que a su vez requiere el apoyo crediticio del FMl. Este apoyo, que a finales de febrero de 2019 ya está planteado y aprobado en los niveles técnicos, se concretará efectivamente en los próximos meses, dando paso a la profundización de un conjunto de medidas combinadas de austeridad fiscal (contra gastos innecesarios y burocratización); la focalización de la inversión pública; inicio de procesos de concesiones de los sectores estratégicos, incluidos los mecanismos de financiamiento vía alianza público-privado, etc.

La parte más débil de las propuestas de reforma es la política productiva no-petrolera, en gran parte por las propias características de una economía de corte primario-extractivo, con baja incorporación tecnológica, insuficiencia dinámica para generar empleo productivo y pronunciada articulación entre sectores. Los intentos del cambio de matriz productiva que impulsó el gobierno de Rafael Correa fracasaron en gran parte, por la propia imposibilidad de lograr resultados en un relativo mediano plazo (8 -9 años), la falta de recursos para sostener la estrategia y por el propio diseño de las políticas excesivamente fiscalistas a partir de incentivos tributarios. Lamentablemente, el gobierno de Moreno no menciona para nada la temática relacionada con el cambio de matriz productiva.

\section{Referencias}

Banco Central del Ecuador (2018). Estadísticas económicas. Información Estadística Mensual, No. 2001. Recuperado de: https://contenido.bce.fin.ec/home1/estadisticas/bolmensual/IEMensual.jsp.

Comisión Económica para América Latina (2018a). Balance Preliminar de las Economías de América Latina y el Caribe. Documento informativo. S.18-01134.

(2018b) Estudio Económico de América Latina y el Caribe. Evolución de la inversión en América Latina y el Caribe: hechos estilizados, determinantes y desafíos de política. LC/ PUB.2018/17-P, Santiago.

(2018c). La ineficiencia de la desigualdad (LC/SES.37/3-P), Santiago

(2017). Panorama Fiscal de América Latina y el Caribe. La movilización de recursos para el financiamiento del desarrollo sostenible. Santiago de Chile.

(2016). Balance Preliminar de las Economías de América Latina y el Caribe 2016. Santiago de Chile.

(2015a). Balance Preliminar de las Economías de América Latina y el Caribe 2015. Santiago de Chile.

(2015b). Panorama de la Inserción Internacional de América Latina y el Caribe. La crisis del comercio regional: diagnóstico y perspectivas. Santiago de Chile.

(2015c). Estudio Económico de América Latina y el Caribe. Desafíos para impulsar el ciclo de inversión con miras a reactivar el crecimiento. Santiago de Chile

Fondo Monetario Internacional (2018). World Economic Outlook WEO), octubre de 2018 (2016a). World Economic Outlook (WEO), abril de 2016

(2016b). América Latina y el Caribe: ¿Se prolongará el actual frente frío? Perspectivas económicas Las Américas, octubre de 2016 tober 2015 .

(2015). World Economic Outlook (WEO): Adjusting to Lower Commodity Prices, Oc-

(2010). World Economic Outlook WEO): Recuperación riesgo y reequilbrio, Octubre 2010

García Álvarez, S. (2016). Sumak Kawsay o Buen Vivir como Alternativa al Desarrollo en Ecuador. Aplicación y Resultados en el Gobierno de Rafael Correa (2007-2014), Quito, Ecuador, Universidad Andina Simón Bolívar y Ediciones Abya Yala.

Instituto Nacional de Estadísticas y Censos (2018a). Encuesta Nacional de Empleo, Desempleo y Subempleo. Indicadores laborales, diciembre 2018. Recuperado de: www.inec. gob.ec

(2018b). Encuesta Nacional de Empleo, Desempleo y Subempleo. Indicadores de pobreza y desigualdad, diciembre 2018. Recuperado de: www.inec.gob.ec

LAVOIE, M. (2009). Introduction to Pos Keynesian Economics, United Kingdom, Palgrave Macmillan.

Santos Alvite, E. (1987). Ecuador, la Década de los Ochenta. Crisis Económica y Ensayo Neoliberal, Quito, Corporación Editora Nacional y Colegio de Economistas de Quito. 